\title{
Feather mites on birds: costs of parasitism or conditional outcomes?
}

\author{
Guillermo Blanco, Department of Biology, Uninersity of Saskatchewan, Saskatoon, Saskatchewan, Canada S7N 0W0 \\ and Instituto de Innestigación en Recursos Cinegéticos (C.S.I.C.), c/Libertad 7 A, E-13004 Ciudad Real, Spain. \\ E-mail: gublanco@hotmail.com \\ José L. Tella, Department of Applied Biology, Estación Biológica de Doñana (C.S.I.C.), Anda. Maria Luisa s/n, \\ E-41013 Senilla, Spain \\ Jaime Potti, Departamento de Biología Animal, Uninersidad de Alcalá, E-28871 Alcalá de Henares, Madrid, Spain \\ Arturo Baz, Departamento de Biología Animal, Uninersidad de Alcalá, E-28871 Alcalá de Henares, Madrid, Spain
}

Feather mites (suborder Astigmata, superfamilies Analgoidea, Pterolichoidea and Freyaniidae) are among the commonest ectosymbionts of birds. Most researchers have assumed they are parasites, having negative effects on hosts. Here we present evidence that suggests that feather mites may not be parasites. We develop a framework for considering conditional outcomes in these interspecific associations, dealing with different kinds of relationships between symbionts. The non-parasitic status of feather mites is supported by a literature review as well as by preliminary data on mites' food. We illustrate symbiotic relationships with a graphical model showing different scenarios in which hosts' cost-benefit relations are determined by the interactions among their symbionts.

Birds are hosts to numerous symbionts, some of which can be parasitic, i.e decreasing the fitness of their hosts. Failure to detect costs of parasitism might be due to methodological problems or analytical limitations, because detrimental effects may be confounded or masked by other factors (e.g. Clayton et al. 1992), including infections by other parasitic taxa (e.g. Merino and Potti 1995) and changes in host behaviour to minimise the costs of being parasitised (Hart 1997). Alternatively, some symbionts assumed to be parasitic might have negligible effects on hosts. This kind of symbionts could be considered as commensals, facultative parasites or facultative mutualists rather than true parasites depending on host condition, the symbiont under study, and the nature of the usually diverse community of symbiotic organisms (Bronstein 1994). In fact, commensalism, where there are neither costs nor benefits to hosts, and mutualism, where both host and symbiont benefit, are common in nature (Thompson 1994) although among birds and their symbionts next to nothing is known about how common they are.
Recently, Proctor and Owens (2000) reviewed the role that mites play in the lives of birds. The best studied mites of birds are detrimental parasites (Proctor and Owens 2000). Among them, some astigmatid mites (suborder Astigmata, order Acariformes) seriously weaken their hosts by feeding on feather pith, tunnelling outwards through the feather, burrowing into the skin and other parts of feather follicles, and invading the lungs, tracheae and air sacs (Proctor and Owens 2000). However, astigmatid mites from the superfamilies Analgoidea, Freyanoidea and Pterolichoidea, also known as feather mites, have been viewed as commensals living on the surface of their hosts' flight feathers and presumably feeding on preen gland oil and material trapped in it (Peterson 1975, OConnor 1982, Gaud and Atyeo 1996). Although this has been assumed rather than demonstrated by diet studies, the assumption is based on strong morphological evidence, i.e. on the nature of the mites' mouthparts that makes mites unable to bite on solid material and constrain them to swallow liquids and small solid materials contained therein (Krantz 1971). Alternatively, feather mites might dissolve food (feathers in this case) and then feed on it, as some other groups of mites do (Proctor and Owens 2000), although this possibility seems unlikely as feather damage attributable to mites has, to our knowledge, never been demonstrated.

Commensal and mutualistic associations between astigmatid mites and both their invertebrate and vertebrate hosts have been long known (OConnor 1982, W. T. Atyeo, pers. comm.). However, most researchers who have studied some aspect of the interaction between feather mites and birds have neglected the possibility that feather mites may not be parasites (e.g., Fowler and Williams 1985, Choe and Kim 1987, 1991, 
McClure 1989a, Poulin 1991, Poiani 1992, Benhke et al. 1995, Ró zsa 1997, Thompson et al. 1997, Harper 1999).

\section{Applying the presumption of innocence to feather mites}

Feather mites are among the commonest ectosymbionts of birds and may exist in large numbers on their hosts (Gaud and Atyeo 1996). What might be invoked as a potential detrimental effect of feather mites is that they may cause irritation or stress that may impair the host immune system as is the case for other symbionts (Esch et al. 1975). This seems plausible although evidence suggests it is not very likely. Removal of feather mites during preening may be minimal as suggested by the fact that hosts seem not to attempt, or cannot, remove mites despite the fact that these show limited movements and live on feathers where they are clearly vulnerable to the host's bill (Choe and Kim 1987, Blanco et al. 1997). Mites' location on the feathers may be regulated by competition between species (Atyeo and Windingstand 1979, Pérez and Atyeo 1984) rather than by predation by the host. This is consistent with the spatial segregation among mite species across hosts' microhabitats (Atyeo and Windingstand 1979, Choe and Kim 1991). Further, feather mites could impose costs on their hosts when they become very abundant as they may constitute up to $10 \%$ of the weight of a feather (Colloff et al. 1997), thus representing an additional, potentially costly burden. However, feather mites are mainly restricted to the flight feathers, which account for only a meager proportion of a bird's weight. Feather mites do not seem to impair host plumage quality as no signs of damage (holes, feather debris, structural alteration of feathers or irritation) are externally visible in the wing and tail of many bird species carefully examined with this aim in Europe and North America (authors' unpubl. data). Further, almost all studies, in which the interaction between feather mites and the body condition of their avian hosts has been addressed, have suggested a commensal, and possibly a mutualistic, rather than a parasitic relationship (Blanco et al. 1997, 1999, Jovani and Blanco 2000, Blanco and Frías 2001, but see Harper 1999).

We have conducted observations under a light microscope aimed at identifying the food consumed by mites. Preliminary results on the identified food found in the gut of two species of feather mite, Pterodectes rutilus (Proctophyllodidae, Pterodictinae) on Barn Swallows Hirundo rustica and Pteronyssoides nuntiaeveris (Avenzoariidae, Pteronyssinae) on Sand Martins Riparia riparia indicate that they feed mostly on algae, fungi and pollen contained in feather oil on the feathers. Algae were present in large numbers (in 100\% and 98\% of Pterodectes rutilus $(\mathrm{n}=126)$ and Pteronyssoides nuntiaeueris $(\mathrm{n}=50)$, respectively). Fungi, including mycelia and spores, were found in $53 \%$ and $38 \%$ of $P$. rutilus and
$P$. nuntiaeueris, respectively, while pollen was only recorded in $8 \%$ of $P$. rutilus. The presence on feathers of all these materials was confirmed by direct observation of feathers under the microscope. These preliminary data support the hypothesis that mites behave as commensal browsers, foraging on the microflora growing on feathers. Taking this information into account, we wonder how these feather mites may stress their hosts up to the point of impairing their immune system and nutritional condition, or interfere with the physiological mechanisms involved in the growth of feathers and the metabolism and deposition of carotenoids, as assumed by Thompson et al. (1997).

\section{Potential benefits provided by feather mites to the host}

By foraging on the feather surface, mites may be removing feather oil and microorganisms contained in it (OConnor 1982) at low or zero cost to the host even when mites are abundant as a consequence of other factors (McClure 1989a, Brawner 1997). Daily production of oil is probably not regulated by mite numbers but by the host's hormonal levels (Jacob and Ziswiler 1982), implying that the consumption of oil by mites may not represent a cost for oil production (but see below). Potential beneficial effects of mites to their hosts may then arise from their control of the numbers of pathogenic microorganisms either directly, by feeding on fungal spores, algae and bacteria that degrade feathers (OConnor 1982), or indirectly by competing for common resources (Jacob and Ziswiler 1982, Price et al. 1986). When hosts cannot preen efficiently due to their weakened or compromised state of health (Clayton 1991, Brawner 1997), or due to beak anomalies, e.g. lesions produced by avian pox viruses and their associated bacteria located around the base of the mandibles (McClure 1989b), old oil and detritus may accumulate on feathers. In both cases, feather mites could increase in numbers and improve the efficiency of feather preening by removing the old oil where pathogenic microorganisms may proliferate to the detriment of feather quality (Hubá lek 1994, Burtt and Ichida 1999).

\section{Conditional outcomes of bird-feather mite interactions}

Costs and benefits of particular host-symbiont interactions may vary greatly due to a number of ecological and life-history factors, thus causing conditional outcomes (Bronstein 1994). A graphical model of the abundance of feather mites and their conditional outcomes from a cost/benefit perspective illustrates this point (Fig. 1). We envision two different situations that may determine the 
outcome of the interaction between birds and their feather mites. First, from the evidence presented above we assume that mites remove feather oil and the microorganisms contained in the oil at little or no cost as long as the host is able to preen efficiently (P, Fig. 1). In this case, food resources provided by the host when distributing oil during preening for feather maintenance and the abundance of microorganisms regularly found on feathers regulate the abundance of mites. Feather mites thus live as commensals without any major costs or benefits to their hosts. Nevertheless, some minor costs or benefits could also occur in this situation, for instance the cost of carrying the weight of the mites during flight and the consumption of oil that could otherwise give flexibility and impermeability to the feathers (Jacob and Ziswiler 1982). As argued above, these potential costs may be assumed to be negligible in healthy individuals and normal preening conditions. On the other hand, benefits could also be found in this situation, e.g. those derived from the consumption by mites of old oil and the detritus and microorganisms that it contains. Another possible benefit is the protection against pathogenic parasites obtained by mites' preemption of resources (Price et al. 1986). These potential benefits to hosts that are able to preen their feathers efficiently are more difficult to assess with the available information. In any case, the difference between benefits and costs (a, Fig. 1) would always be low.

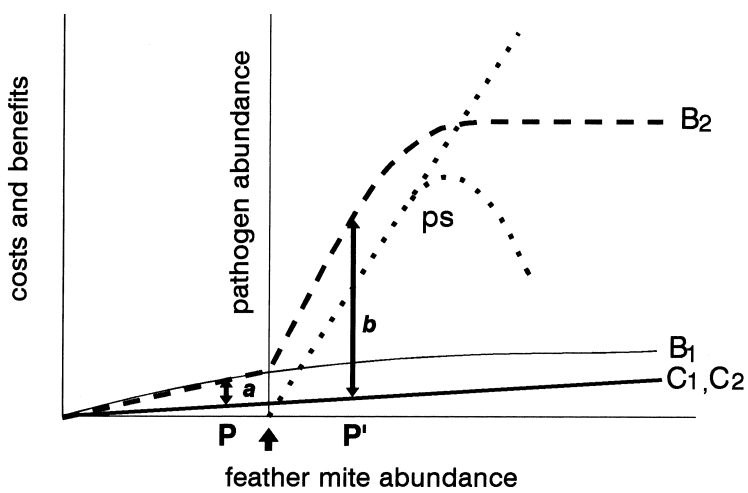

Fig. 1. Graphic model of feather mite abundance and associated costs and benefits to hosts. Two different situations may determine the outcome of the interaction between birds and their feather mites. In the first, feather mites live without causing any major cost $\left(C_{1}\right)$ or benefit $\left(B_{1}\right)$ to their hosts when these are able to preen their plumage efficiently $(\mathrm{P})$. The difference between costs and benefits (a) could nevertheless vary slightly as mite abundance increases. In the second situation, mite abundance may increase when their host is unable to preen efficiently $\left(\mathrm{P}^{\prime}\right)$ due to an infection by a highly detrimental pathogen, a deformed beak, or both (arrow). The abundance of feather mites and other, potentially pathogenic, symbionts (ps) increase with the amount of feeding resources accumulated on feathers. In this scenario, the costs of an increasing mite abundance remain negligible $\left(\mathrm{C}_{2}\right)$ but benefits $\left(B_{2}\right)$ increase in the presence of a third pathogenic species with which the mites compete for resources, with a net benefit to the host (b) and a variable effect on the abundance of the third species.
In the second scenario ( $\mathrm{P}^{\prime}$, Fig. 1), when their host is unable to preen efficiently because of infections by highly detrimental pathogens, a deformed beak, or both (Clayton 1991, McClure 1989a, Brawner 1997) mites may become very abundant because, in this situation, old oil and detritus will accumulate on the feathers. For instance, the abundance of feather mites increased after hosts were experimentally infected with coccidia, but mites did not affect plumage colour (Brawner 1997). Preening does not necessarily imply removing mites because their size as well as morphological and behavioural adaptations for attachment to feathers may preclude this (Choe and Kim 1991) or because birds do not attempt to remove these mites (Blanco et al. 1997) but to remove oil and microorganisms. In this situation, increasing populations of feather mites may compete for resources with pathogenic symbionts, which may proliferate due to an excess of oil and detritus on the feathers, e.g. keratinophilic fungi and bacteria. Thus, mites may increase strongly in abundance at low or no cost to the host while indirectly controlling the proliferation of opportunistic pathogens which, for instance, may degrade feathers at a high cost to the host (Hubá lek 1994, Burtt and Ichida 1999). Mites may also directly affect the pathogens, i.e. bacteria, algae or fungi by consuming them together with the feather oil. Therefore, also very abundant mite populations may offer benefits to the hosts at low or no cost. In this case they may be considered facultative mutualists.

\section{Ecological and evolutionary perspectives}

In conclusion, we envision a complex of interactions related to different ecological and life-history factors and including the possibility of conditional outcomes in bird-feather mite interactions. As Bronstein (1994) highlighted for host-symbiont interactions, outcomes in this particular system must be extremely dynamic because they depend on many factors and different symbionts acting simultaneously at different intensities on the same host.

We suggest that the relationships between feather mites and other symbionts living on the feathers of their avian hosts may be an ideal model to investigate experimentally conditional outcomes of mutualistic interactions. Research for a better understanding of the diversity of potential interactions of feather mites with their hosts should include identifying the environmental, individual and population conditions affecting host and symbiont and, in addition, the presence and abundance of other interacting species. The hormonal regulation of uropygial secretions could be assessed through hormonal implants (Saino et al. 1995), and other host traits, such as preening ability, could be manipulated (e.g. Clayton 1991). The presumed close balance between the small costs and benefits imposed by feather mites in 
normal conditions (a, Fig. 1) may be determined by experimentally adding and removing mites. Finally, the experimental inclusion or control of a third pathogenic symbiont (e.g. coccidia, avian pox, detrimental ectoparasites) would allow to ascertain changes in preening efficiency and other self-maintenance activities, as well as the existence of direct and indirect competition between ectosymbionts, and thus the actual nature of the derived conditional outcomes.

Acknowledgements - During writing, G.B. and J.L.T. were supported by grants of the Ministerio Españ ol de Educación y Ciencia, and J.P. by project DGICYT PB97-1233-C02-01. The manuscript benefited from comments by B. M. OConnor, G. Hill, J. E. Loye, M. Zuk, C. W. Thompson and two anonymous referees.

\section{References}

Atyeo, W. T. and Windingstand, R. M. 1979. Feather mites of the greater sandhill crane. - J. Parasitol. 65: 650-658.

Benhke, J. M., McGregor, P. K., Shepherd, M., Wiles, R., Barnard, C., Gilbert, F. S. and Hurst, J. L. 1995. Identity, prevalence and intensity of infestation with wing feather mites on birds (Passeriformes) from the Setubal Peninsula of Portugal. - Exp. Appl. Acarology 19: 443-458.

Blanco, G., Tella, J. L. and Potti, J. 1997. Feather mites on group-living Red-billed Choughs: a non-parasitic interaction? - J. Avian Biol. 28: 197-206.

Blanco, G., Seoane, J. and de la Puente, J. 1999. Showiness, non-parasitic symbionts, and nutritional condition in a passerine bird. - Ann. Zool. Fenn. 36: 23-28.

Blanco, G. and Frías, O. 2001. Symbiotic feather mites synchronize dispersal and population growth with host sociality and migratory disposition. - Ecography 24: 113-120.

Brawner, W. R. III. 1997. The effects of coccidial and mycoplasmal infection on plumage pigmentation in male house finches (Carpodacus mexicanus): a test of the Hamilton-Zuk hypothesis. - M.Sc. thesis, Auburn University, AL, USA.

Bronstein, J. L. 1994. Conditional outcomes in mutualistic interactions. - Trends Ecol. Evol. 9: 214-217.

Burtt, E. H. and Ichida, J. M. 1999. Occurrence of feather-degrading bacilli in the plumage of birds. - Auk 116: 364372.

Choe, J. C. and Kim, K. C. 1987. Community structure of arthropod ectoparasites on Alaskan seabirds. - Can. J. Zool. 65: 2998-3005.

Choe, J. C. and Kim, K. C. 1991. Microhabitat selection and adaptation of feather mites (Acari: Analgoidea) on murres and kittiwakes. - Can. J. Zool. 69: 817-821.

Clayton, D. H. 1991. Coevolution of avian grooming and ectoparasite avoidance. - In: Loye, J. E. and Zuk, M. (eds). Bird-Parasite Interactions. Ecology, Evolution and Behaviour. Oxford University Press, Oxford, pp. 258-289.

Clayton, D. H., Pruett-Jones, S. G. and Lande, R. 1992. Reappraisal of the interspecific prediction of parasite-mediated sexual selection: opportunity knocks. - J. theor. Biol. 157: 95-108.

Colloff, M. J., Merrett, T. G., Merrett, J., McSharry, C. and Boyd, G. 1997. Feather mites are potentially an important source of allergens for pigeon and budgerigar keepers. Clin. Exp. Allergy 27: 60-67.

Esch, G. W., Gibbons, J. W. and Bourque, J. E. 1975. An analysis of the relationship between stress and parasitism. - Amer. Midl. Natur. 93: 339-353.
Fowler, J. A. and Williams, R. 1985. Population dynamics of Mallophaga and Acari on reed buntings occupying a communal winter roost. - Ecol. Entomol. 10: 377-383.

Gaud, J. and Atyeo, W. T. 1996. Feather mites of the world (Acarina, Astigmata): the supraspecific taxa. - Ann. Sci. Zool. 277: 1-193.

Harper, D. G. C. 1999. Feather mites, pectoral muscle condition, wing length and plumage coloration of passerines. Anim. Behav. 58: 553-562.

Hart, B. L. 1997. Behavioural defence. - In: Clayton, D. H. and Moore, J. (eds). Host-Parasite Evolution. General Principles and Avian Models. Oxford University Press, Oxford, pp. 59-77.

Hubá lek, Z. 1994. Pathogenic microorganisms associated with free-living birds (a review). - Prirodovedne Ved. Ceske Republiky v Brno 5: 1-74.

Jacob, J. and Ziswiler, V. 1982. The uropygial gland. In: Farner, D. S., King, J. R. and Parkes, K. C. (eds). Avian Biology. Vol. 4. Academic Press, New York, pp. 199-324.

Jovani, R. and Blanco, G. 2000. Resemblance within flocks and individual differences in feather mite intensity on Long-tailed tits Aegithalos caudatus. - Écoscience 7: 428432.

Krantz, G. W. 1971. Manual of Acarology. - Oregon State Univ. Press, Oregon.

McClure, H. E. 1989a. Occurrence of feather mites (Protophylloidae) among birds of Ventura County Lowlands, California. - J. Field Ornithol. 60: 431-450.

McClure, H. E. 1989b. Epizootic lesions of house finches in Ventura County, California. - J. Field Ornithol. 60: 421430.

Merino, S. and Potti, J. 1995. Mites and blowflies decrease growth and survival in nestling pied flycatchers. - Oikos 73: 95-103.

OConnor, B. M. 1982. Evolutionary ecology of astigmatid mites. - Annu. Rev. Entomol. 27: 85-409.

Pérez, T. M. and Atyeo, W. T. 1984. Site selection of feather and quill mites of Mexican parrots. - In: Griffiths, D. A and Bowman, C. E. (eds). Acarology. Vol. VI. Ellis Horwood, Chichester, pp. 563-570.

Peterson, P. C. 1975. An analysis of host-parasite associations among feather mites (Acari: Analgoidea). - Misc. Publ. Entomol. Soc. Amer. 9: 237-242.

Poiani, A. 1992. Ectoparasitism as a possible cost of social life: a comparative analysis using Australian passerines (Passeriformes). - Oecologia 92: 429-441.

Poulin, R. 1991. Group living and infestation by ectoparasites in passerines. - Condor 93: 418-423.

Price, P., Westoby, M., Rice, B., Atsatt, P. R., Fritz, R. S., Thompson, J. N. and Mobley, K. 1986. Parasite mediation in ecological interactions. - Annu. Rev. Ecol. Syst. 17: 487-505.

Proctor, H. and Owens, I. 2000. Mites and birds: diversity, parasitism and coevolution. - Trends Ecol. Evol. 15: 358364.

Ró zsa, L. 1997. Wing feather mite (Acari: Proctophyllodidae) abundance correlates with body mass of passerine hosts: a comparative study. - Can. J. Zool. 75: 1535-1539.

Saino, N., Møller, A. P. and Bolzern, M. 1995. Testosterone effects on the immune system and parasite infestations in the barn swallow (Hirundo rustica): an experimental test of the immunocompetence hypothesis. - Behav. Ecol. 6: 397 404.

Thompson, J. N. 1994. The Coevolutionary Process. - University of Chicago Press, Chicago.

Thompson, C. W., Hillgarth, N., Leu, M. and McClure, H. E. 1997. High parasite load in house finches (Carpodacus mexicanus ) is correlated with reduced expression of a sexually selected trait. - Am. Nat. 149: 270-294. 